Onderzoek naar de beteekenis en de vooruitzichten van den Nederlandschen handel in ruwe tabak, samengesteld door de Economische Afdeling van Preijer \& de Haan in opdracht van de Vakgroep Groothandel in Tabak.

$H$. G. Hagelen, Een en ander over belastingen in verband met levensverzekeringen, Litg. v. Soeren \& Co. Amsterdam, prijs $f$ 4.50.

Drs J. A. Baart, Bedrijfseconomische Monographieën, De calculatie in de onderneming, Uitg. Stenfert Kroese, Leiden.

\title{
REPERTORIUM VAN LITERATUUR OP HET GEBIED VAN ACCOUNTANCY EN BEDRIJFSHUISHOUDKUNDE
}

\author{
Redactie: Stichting Centrale \\ Dienst voor Bedrijfs- \\ documentatie
}

\section{TIJDSCHRIFTENREPERTORIUM}

\section{A. ACCOUNTANCY}

\section{HET ACCOUNTANTSBEROEP}

\section{Het voorschrift}

Mey, A. - Schr. pleit voor een periodieke revisie van het wetboek. De juridische adviseurs van Napoleon, de geestelijke vaders van het wetboek - de code Napoleon kenden geen accountants, maar alleen ambtenaren in een politiestaat. De juridische zijde van de accountant in overheidsdienst is nog steeds niet geregeld. Volgens de oude bepaling van het wetboek zou men deze ambtenaren, administratieve- of bedrijfseconomische opsporingsambtenaren moeten noemen. Volgens schr. is de accountant geen ambtenaar volgens bedoelde wetsbepaling. $\mathrm{Er}$ ontstaat een controverse tussen algemene bepalingen en voorschriften uit speciale gebieden van het sociale leven. De laatste verdienen verreweg de voorkeur.

A II 4

Financicel Overheidsbeheer, No. 7, Juli 1948

\section{B. BEDRIJPSHUISHOUDKUNDE}

\section{a. ALGEMENE BEDRIJPSHUISHOUDKUNDE}

\section{WAARNEMINGSMIDDELEN}

De plasts van de statistische afdeling in de onderneming

L u y k, H. - De variatie, welke in de practijk t.o.v. de plaats van de statistische afdeling in de structuur van het bedrijf blijkt voor te komen, geeft aan, dat dit vraagstuk nog geenszins is opgelost.

Schrijver geeft het voor en tegen van verschillende met name genoemde mogelijkheden daarbij steunende op de Zwitserse auteur Donzallaz en komt tot de conclusie, dat de meest wenselijke vorm in vele gevallen die is, waarbij de bedrijfsstatisticus aan de administratieve functie in het bedrijf is ondergeschikt gemaakt. Dit impliceert de noodzaak on bij de opleiding voor hogere administratieve functies meer aandacht aan de statistische methodenleer te schenken.

$\mathrm{B}$ a III 3 Tijdschrift voor Efticientie en Documentatic No. 8, Augustus 1948

Vereenvoudiging van de loonadministratie door wijziging in de wettelijke sociale en fiscale maatregelen

Diesbergen, B. en B otti, E. M. H. - Samenvatting van een rapport van de Studiekring voor Moderne Kantoortechniek, Bedrijfsgroep van het Nederlands Instituut voor Efficiency. In dit rapport worden voorstellen gedaan ter herziening van de wettelijke sociale en fiscale maatregelen, daar deze de belangrijkste hinderpaal zijn voor vereenvoudiging van de loonadministratie.

B a III 3 Tijdschrift voor Efficiency en Documentatie No. 8. Augustus 1948 


\section{Contrôlemethoden bij de toepassing van boekhoudmachines}

O orschot, J. M. va n - In aansluiting op het vorige artikel over bovengenoemd onderwerp in het Juli-nummer worden nu enkele methoden voor het controleren van oude en nieuwe saldi behandeld.

le. Visuele contrôle.

2e. Voor- en natelling oude en nieuwe saldi.

3e. Mutatiecontrōle.

4e. Gecomprimeerde dual-run contròle.

5e. Zuivere oud saldo contrôle.

B a III 3

Kantoormachinenieuws No. 8. Augustus 1948

\section{LEER VAN DE KOSTPRIJS EN DE PRIJSVORMING}

De last-in - first-out methode als middel ter berekening van de fiscale winst

Blik, J. F. - In Amerika, zowel als in België is op verzoek een methode van winstberekening toegestaan, die zeer afwijkt van die welke hier te lande toegepast mag worden, n.l. berekening op grond van uitgaafprijs. De Last-in - first-out methode wordt besproken en op sommige punten vergeleken met de vervangingswaardetheorie en de theorie van de ijzeren voorraad.

B a IV 2

De Naamloze Vennootschap No. 4/5, Juli/Augustus 1948

\section{Transactie- en voorraadwinsten resp. verliezen}

Me y, J. L. - De vervangingswaardetheorie is ook van belang voor de scheiding tussen transactie- en voorraadresultaten. Aan de hand van een aantal eenvoudige voorbeelden wordt nagegaan of en waarom een winst wel of niet voor uitkering vatbaar is en van de verliezen of deze wel of niet ten laste van de vermogensegalisatierekening kunnen worden gebracht. Voorts wordt critiek geleverd op de stelling van Prof. H. J. v. d. Schroeff in "Leer van de Kostprijs", die luidt, dat in gevallen waarin vervanging onmogelijk of economisch irrationeel is, de offers bij de ruil door de uitgaafprijs worden bepaald. Volgens schr. moet het criterium voor de doelmatigheid van de ruil in de alternatieve aanwendingsmogelijkheid gezocht worden.

B a IV 2 Maandblad voor Bedrijtsadministratie No. 616, Juli 1948

De verhoging der vermakelijkhedenbelasting

Polm a n, G. B. W. - In het wetsontwerp Belastingherziening 1946 werd bepaald, dat ten behoeve van het Rijk, van een bepaald soort diensten, welke bestaan uit het geven van toegang tot vertoningen, voorstellingen, uitvoeringen, wedstrijden en andere vermakelijkheden, een weeldebelasting kon worden geheven van ten hoogste $25 \%$. Een gelijkheffingspercentage voor diverse soorten vermakelijkheden is evenwel bezwarend. Daarom is de minister, bij een circulaire van 19 November 1947 nr. U 59283, afd. B.B. Bur. Fin., overgegaan tot de instelling van een gedifferentieerd heffingspercentage. Deze nieuwe regeling wordt in dit artikel besproken.

B a IV 7

Gemeente Financiën. No. 7, Juli 1948

\section{Belastingvrijstelling van staatsbedrijven}

Elbers, C. H. - De gevolgen van de belastingvrijstelling zijn afhankelijk van het feit of die belasting al dan niet een kostenbestanddeel geweest zou zijn. In het ene geval leidt de vrijstelling tot een lagere aanbiedingsprijs van het product, in het andere tot een grotere winst. Dit laatste kan ten goede komen aan de interne financiering. Enkele facetten hiervan, zoals nivellering van de uitkeringen en aflossing van schulden, worden aan een korte bespreking onderworpen. Belastingvrijstelling van staatsbedrijven, die met gelijksoortige particuliere bedrijven moeten concurreren is niet te verenigen met een stelsel van "fair competition". Tot slot wordt de fiscale politiek t.a.v. de drie grootste staatsbedrijven n.l. de Staatsmijnen, de N.V. Ned. Spoorwegen en de P.T.T. besproken. B a IV 7

Openbare Financiën, No. 3, 1948

\section{LEER VAN DE FINANCIERING}

\section{De koop-huur overeenkomst}

S a nders, P. - De koop-huur overeenkomsten, de purchase-lease contracten, hebben in de Verenigde Staten een grote vlucht genomen. Onder de koophuur overeenkomst wordt verstaan de overeenkomst, waarbij de eigenaar zijn onroerend goed verkoopt aan een belegger en het tegelijkertijd voor een lange termijn in huur neemt. Dit systeem biedt voor beide partijen voordelen. Vooral de verzekeringmaatschappijen maken van deze beleggingsmogelijkheid, die een behoorlijk rendement oplevert, ruimschoots gebruik.

$\mathrm{B}$ a $\mathrm{V} 1$

De Naamloze Vennootschap No. 4/5, Juli/Augustus 1948

m a b blz. 294 


\section{LEER VAN DE ORGANISATIE}

\section{Het affectief appèl in de reclame}

Le nnep, D. J. van - Verhouding tussen de psychologie en de reclame. De psycholoog is geen criticus, doch kan helpen bij de statistische beoordeling van verschillende factoren. Enkele algemene psychologische principes, welke nodig zijn voor een doelmatige reclame-campagne worden besproken.

$\mathrm{B}$ a VI 11

Ariadne No. 7, Juli-Augustus 1948

\section{Resultatencontrôle}

Goudria an, J. - Bij de reclame moeten twee doeleinden worden onderscheiden, n.l. het stimuleren van de afzet van de onderneming in kwestie en het scheppen van een bepaalde behoefte. De beste techniek om de resultaten te controleren is een algemene enquête. Eerst in de dertiger jaren is men de invloed van de reclame op de prijsvorming bij de marktanalyse gaan betrekken. Tot slot worden de maatschappelijke voor- en nadelen van de reclame besproken.

B a VI 11

Ariadne No. 7, Juli-Augustus 1948

\section{Het typewerk in "De Bijenkorf”}

Kon ing, J. A. A. - Opsomming van de voordelen verbonden aan typewerk. Korte behandeling van de plaats welke het typewerk in de organisatie van het bedrijf inneemt.

B a VI 13

Tijdschrift voor Efficientie en Documentatie No. 8, Aug. 1948

\section{What supervisors want}

Selfe, E. M. - Most managements have a lot to say about the foreman and supervisor being „part of management". Here a first line supervisor points to some of the gaps between what management says to the foreman and supervisor and what it actually does, and tells what supervisors want from management..

B a VI 16

Personnel Journal No. 8. Februari 1948

\section{Variabele budgettering}

S i e brands, G. H. L. F. - Reeds Drs A. M. Groot bepleitte in Ec. Stat. Berichten van 1 Mei 1946, de vervanging in de overheidsadministratie van de vaste budgetten door variabele taakstellende budgetten. Om de comptabele ambtenaar enig inzicht in deze, voor hem zo noodzakelijke materle, te geven, wordt in dit artikel een beknopte beschouwing aan dit onderwerp gewijd.

B a VI 18

Financieel Overheidsbeheer No. 7, 15 Juli 1948

\section{LEER VAN DE ARBEIDSVOORWAARDEN}

\section{Collective bargaining-grass roots or ivory tower}

S te phens, H. T. - The most satisfactory and effective decisions are usually those which are arrived at by the democratic process, in which every group with a responsibility for the matter in hand is represented. Here is the story of how a manufacturing company used democratic process to advantage in annual negotiations for the labor agreement.

B a VII 4

Personnel Journal No. 8. Februari 1948

\section{Job Evaluation Discussion}

E d. - A few years ago personnel people were not troubled by anything so technical and controversial as job evaluation. Today, every personnel worker must become familiar with it; learn the technical details and the strategies necessary to secure its acceptance - by executive ranks, supervision, union and worker. $\mathrm{B}$ a VII 5
Personnel Journal, No. 1, Mei 1948

De betekenis van de arbeidspsychologische research voor de practische personeelsopleidingen

Koekebakker, J. - De schrijuer wijst er op, dat op het gebied van de arbeidspsychologie een onmetelijk terrein braak ligt. Hij geeft een opsomming van problemen, welker oplossing door de arbeidspsychologie kan worden bevorderd.

B a VII 5

Tijdschrift voor Efficientie en Documentatie No. 3, 1948

Survey of the training and qualifications of personnel executives

Parks, D. S. - A study of the education and experience of eighty-four personnel executives in leading American industries and their suggestions for an industrial training program and for a university course.

B a VII 7

Personnel Journal, No. 7. Januari 1948 


\section{Arbeidsvreugde}

Rodenhuis, A. L. - Schrijver behandelt de factor arbeidsvreugde als meest doelmatig arbeidsincentief.

Arbeidsvreugde is een onmisbaar element voor de welvaart in een bedrijf en om deze te verkrijgen moet allereerst de belangstelling van het personeel voor het bedrijf worden gewekt. Hierbij hangt veel af van de houding van de leiding. Schrijver gaat hler nader op in.

B a VII 8

Bedrijfsuervoer No. 15, 1948

\section{De wijziging en aanvulling van de pensioenwet}

J a n s e n, M. J. - In aansluiting op het artikel over bovengenoemd onderwerp in no. 7 (1948), waarin de verhoging der pensioen-maxima voor het eigen - en voor het weduwen - en wezenpensioen en de regeling inzake inkoop van diensttijd besproken worden, volgt nu de behandeling van enkele problemen, die betrekking hebben op het ambtenaarschap en de pensioenberekening. Voorts een beschouwing over de volgende onderwerpen: a) het recht op pensioenen. b) de terugbetaling aan het algemecn burgerlijk pensioenfonds door een aantal gemeenten, die voor het eigen pensioen harer ambtenaren risico droegen. c) de kindertoeslag voor gepensionneerden.

B a VII 9

Financieel Overheidsbeheer, No. 8, Aug. 1948

\section{Het ziekenfondsbesluit}

$\mathrm{H}$ a z e $\mathrm{z}$ e t, M. A. J. - Schrijver levert critiek op het ziekenfondsbesluit. De ongehuwden met lonen tussen $f 25$, - en $f 72$, - per week betalen belangrijk meer dan een vrijwillig verzekerde. Dit is geen sociale wet doch een extra belasting. Het maximum dagloon, dat voor premie-berekening in aanmerking komt, moet daarom lager worden gesteld. Voorts wordt de verhouding van fonds tot arts en van arts tot patiënt gecritiseerd. De artsen zouden in de gelegenheid moeten worden gesteld een bepaald bedrag per visite aan hun patiënten in rekening te brengen.

B a VII 9 Maandblad voor Sociaal Economische Wetenschappen. No 89, Aug. 1948

\section{b. BIJZONDERE BEDRIJVEN}

\section{INDUSTRIE}

\section{De Nederlandse katoenindustrie en de Benelux}

Gelderman. J. - Verschillen tussen België en Nederland. In België is de spincapaciteit $\pm 1 \frac{1}{2}$ zo groot. de weefcapaciteit is ongeveer gelijk. België heeft daarom een grote garenexport. Nederland moet importeren. De uitvoer van België concentreert zich op landen met een Europese bevolking, die van Nederland op landen met een tropische bevolking. De Belgische industrie heeft zich sneller kunnen herstellen dan de Nederlandse. Op vele gebieden vullen beider industrieën elkaar aan. Daarnaast zijn er gebieden van concurrentie. Wanneer op 1 Jan. 1950 de vrije handel der Beneluxpartners een feit zal worden, zal men over moeten gaan tot wijziging der binnenlandse beperkingen op textielgebied.

$\mathrm{B}$ b V 13

Economisch-Statistische Berichten No. 1630, 4 Augustus 1948

\section{Interne bedrijfsorganisatie voor de Papierverwerkende Industrie}

Ha l, A. M. C. va n - Schrijver geeft enige richtlijnen voor een doelmatige bedrijfsorganisatie. Bij de taakverdeling maakt hij onderscheid tussen:

1. leiding gevende arbeid;

2. toezichthoudende arbeid:

3. uitvoerende arbeid.

Hij wijst er op, dat het toepassen van dit schema slechts nuttig is, wanneer dit wordt voorafgegaan door taakanalyse en personeelsselectie. $\mathrm{B}$ b V 17

De Papierwereld, No. 2, 1948

\section{FINANCIERINGSINSTELLINGEN}

\section{De Gemeentelijke Hypotheekbank}

R e d. - Er wordt gewezen op de behoefte, die er in het huidige stadium van de na-oorlogse ontwikkeling aan gemeentelijke hypotheekbanken bestaat. Van rentabiliteit van het in de woningen gestoken vermogen, is geen sprake meer. Het aanbod van vermogen schiet dan ook ernstig tekort. Vandaar, dat ingrijpen van gemeentewege noodzakelijk is. Het terrein waarop de gemeente zich te dien aanzien zou kunnen bewegen wordt besproken. 